\title{
Enhanced Thermal Insulation and Flame-Retardant Properties of Polyvinyl Alcohol-Based Aerogels Composited with Ammonium Polyphosphate and Chitosan
}

\author{
MinYi Luo, ${ }^{1}$ Jiayou Xu $\mathbb{D D}^{1}{ }^{1}$ Shu Lv, ${ }^{1}$ XueFeng Yuan, ${ }^{2}$ and Xiaolan Liang ${ }^{1}$ \\ ${ }^{1}$ School of Chemistry \& Chemical Engineering, Guangzhou University, Guangzhou, China \\ ${ }^{2}$ Institute for Systems Rheology, Guangzhou University, Guangzhou, China \\ Correspondence should be addressed to Jiayou Xu; xujiayou516@163.com
}

Received 29 January 2021; Revised 23 March 2021; Accepted 16 May 2021; Published 29 May 2021

Academic Editor: Qinglin Wu

Copyright (C) 2021 MinYi Luo et al. This is an open access article distributed under the Creative Commons Attribution License, which permits unrestricted use, distribution, and reproduction in any medium, provided the original work is properly cited.

\begin{abstract}
Polyvinyl alcohol- (PVA-) based aerogels have attracted widespread attention owing to their low cost, eco-friendliness, and low density. However, the applications of PVA-based aerogels are limited by their flammability. In this study, a flame retardant, ammonium polyphosphate (APP), and a biopolymer, chitosan (CS), were added to polyvinyl alcohol (PVA), and the polymer was further crosslinked using boric acid $\left(\mathrm{H}_{3} \mathrm{BO}_{3}\right)$. In the PVA aerogels, the negatively charged APP and positively charged CS formed a polyelectrolyte complex (PEC) through ionic interaction. Cone calorimetry and vertical burning tests (UL-94) indicated that the PVA composite aerogels have excellent flame retardancy; they could decrease the heat release rate, total heat release rate, and carbon dioxide $\left(\mathrm{CO}_{2}\right)$ generation. Both $\mathrm{PVA} / \mathrm{H}_{3} \mathrm{BO}_{3}$ and APP-CS in the composite aerogel could be burned to carbon, and the foamed char layer could act together to impart the PVA composite aerogels with good flame retardancy. Further, the decrease in the temperature at the backside of the aerogels with increasing APP-CS content, as determined by the flame-spraying experiment, indicated that the PVA-based aerogels with APP-CS can also serve as thermal insulation materials. This work provides an effective and promising method for the preparation of PVA-based aerogels with good flame retardancy and thermal insulation property for construction materials.
\end{abstract}

\section{Introduction}

With rapid economic development, the demand for energy is growing. In particular, energy consumption related to buildings has continuously increased over the past decades [1]. Therefore, energy conservation in buildings is a very important development trend. Currently, wall insulation is most commonly used for this purpose globally. For example, adding a polymer-based aerogel material between walls can effectively preserve house heat and provide insulation. Polymer-based aerogels have attracted significant attention as construction materials owing to their unique advantages, such as low density, high specific surface area, and low thermal conductivity [2-5]. Among the various polymer matrices, water-soluble polyvinyl alcohol (PVA) is a versatile and low-cost polymer [6] that can be used to prepare aerogels. However, its application as a building material is limited by its flammability. The fire hazards associated with the application of such polymer materials can result in loss of life and property $[7,8]$. Therefore, it is necessary to develop materials with good flame retardancy and thermal insulation as construction materials for modern buildings, which remains a significant challenge.

A common method to improve the fire resistance and thermal stability of polymer materials is to incorporate fireretardant materials as additives. Intumescent flame retardants (IFRs) are the most widely used additives for forming foamed char on the surface of burning materials. This induces a barrier effect to prevent or mitigate heat transfer from the heat source to the polymer and mass transfer from the external surface of the polymer to the bulk of the polymer. An IFR consists of three components: an acid source, gas source, and carbon source. Ammonium polyphosphate (APP) is typically used as an acid and gas source in IFRs. It 


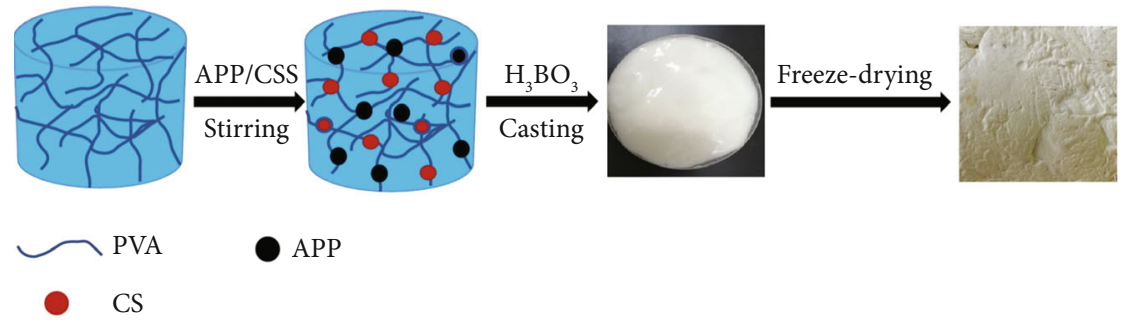

Figure 1: Preparation procedure of the PVA composite aerogel.

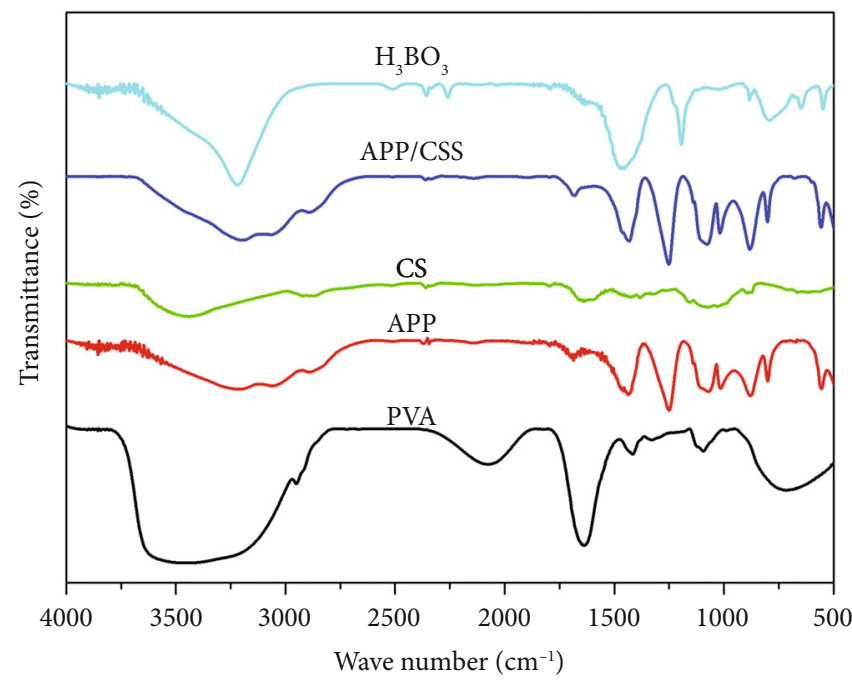

Figure 2: FTIR spectra of PVA, APP, CS, APP-CS, and $\mathrm{H}_{3} \mathrm{BO}_{3}$.

is generally composited with other additives to improve the flame retardancy of the polymers [9]. Further, chitosan (CS) is a highly abundant and naturally occurring biopolymer that is composed of amine-containing 2-deoxyglucan. It is thought to be a promising green charring agent because of the presence of multiple hydroxyl and amino groups in its structure $[10,11]$.

Herein, we prepared flame-retardant PVA-based aerogels with different loadings of APP-CS. The negatively charged APP and positively charged CS act as a complementary pair to form a polyelectrolyte complex (PEC) that can serve as a flame retardant. The microstructure, flammability, and thermal insulation properties of the prepared PVA-based aerogels were evaluated. The results demonstrate that the composite aerogels developed in this work have great potential as heat insulation and flame-retardant materials.

\section{Materials and Methods}

2.1. Materials. Poly(vinyl alcohol) (PVA) with a polymerization degree of 1000 or more and a saponification degree of $>99$ mol\% (PVA-1799) was supplied by Kelong Chemical Reagent Corporation (Chengdu, China). APP was purchased from Macklin Reagent (Shanghai, China). CS (deacetylation degree, $\geq 95 \%$ ) was obtained from Aladdin Chemistry Co., Ltd. (Shanghai, China). Boric acid was procured from Xilong Science Co., Ltd. (Shantou, China). All the chemicals were of laboratory grade and were utilized as received without further purification unless otherwise specified.

2.2. Preparation of the PVA Composite Aerogels. The preparation process of the PVA composite aerogels is schematically illustrated in Figure 1. $8 \mathrm{wt} \%$ PVA aqueous solution was prepared by dissolving $8 \mathrm{~g}$ PVA in $92 \mathrm{ml}$ DI water at $95^{\circ} \mathrm{C}$ under stirring for $3 \mathrm{~h}$. To prepare a PVA/APP-CS solution, $0 \mathrm{~g}, 5 \mathrm{~g}, 10 \mathrm{~g}$, and $15 \mathrm{~g}$ APP-CS (APP : CS = $3: 1$ mass ratio) were mixed with $100 \mathrm{ml}$ of $8 \mathrm{wt} \%$ PVA solution at $14000 \mathrm{rpm}$ (A-555, INAYOU, China). Then, dissolve $0.8 \mathrm{~g}$ of boric acid in $10 \mathrm{ml}$ of water and add to the above solution to prepare the hydrogels. After that, the resulting hydrogels were cast into a glass dish and frozen in a refrigerator, followed by freeze-drying in an FD-1A-50 freeze dryer (Yuming Instrument Co., Ltd., Shanghai, China) at $-40^{\circ} \mathrm{C}$ under vacuum. And the as-obtained PVA composite aerogels are denoted as $\mathrm{PVA} / \mathrm{H}_{3} \mathrm{BO}_{3}, \mathrm{PVA} / 5 \mathrm{APP}-\mathrm{CS} / \mathrm{H}_{3} \mathrm{BO}_{3}$, PVA/ $10 \mathrm{APP}-\mathrm{CS} / \mathrm{H}_{3} \mathrm{BO}_{3}$, and PVA/15APP-CS/ $\mathrm{H}_{3} \mathrm{BO}_{3}$.

2.3. Characterization. Fourier-transform infrared (FTIR) spectra were recorded with a VERTEX70 spectrometer (Bruker Instrument Co., Ltd., Dresden, Germany) with thin films of $\mathrm{KBr}$ at room temperature. The measurement was carried out in the optical range of $4000-500 \mathrm{~cm}^{-1}$.

$\mathrm{X}$-ray diffractometry (XRD) was performed on a $\mathrm{Neo}$ Confucianism D/Max-2400 diffractometer (Rigaku, Tokyo, 


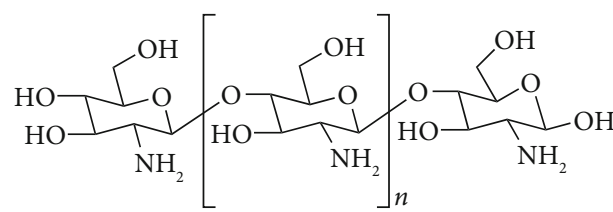

CS

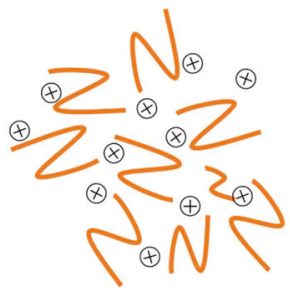

CS

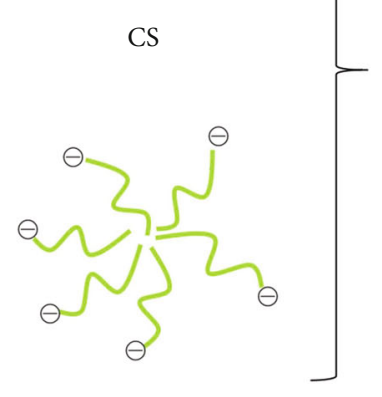

APP

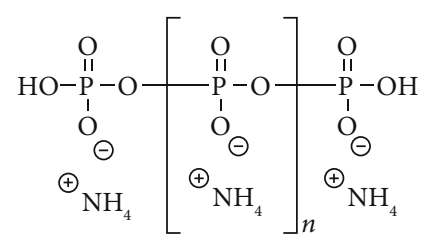

APP

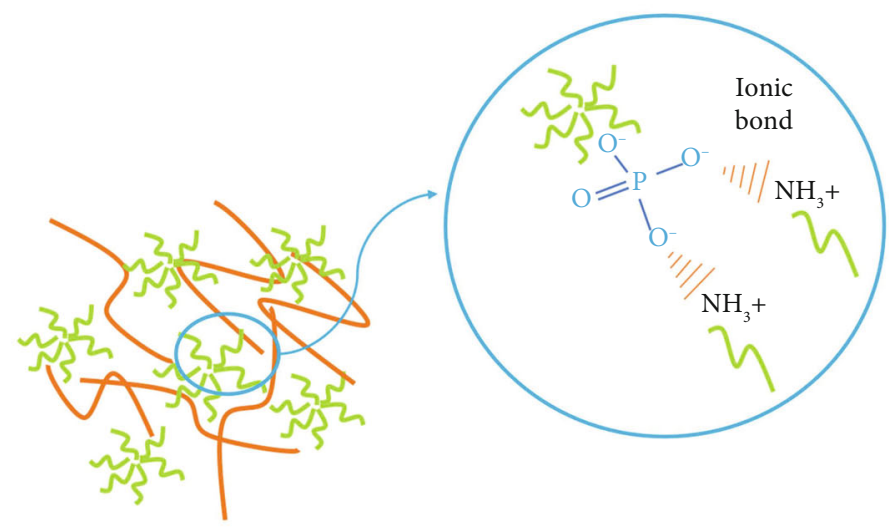

PEC

FIGURE 3: Schematic illustration of the interaction between APP and CS.

Japan), and the $2 \theta$ scans were conducted in the range of $5^{\circ}$ to $80^{\circ}$.

The morphology of the samples was observed by scanning electron microscopy (SEM) using JSM-7001F (Japan Electron Optics Laboratory Co., Ltd., Tokyo, Japan).

Thermogravimetric analysis (TGA) was performed on a TGA400 thermo-analyzer instrument (PerkinElmer, Inc., Fremont, CA, USA) from room temperature to $700^{\circ} \mathrm{C}$ at a linear heating rate of $10^{\circ} \mathrm{C} \cdot \mathrm{min}^{-1}$ under nitrogen atmosphere.

The fire behavior of the aerogels was characterized by the UL-94 test (ASTM D-635-77) and the cone calorimeter test (CCT). The UL-94 test was performed on a CZF-2 vertical burning test instrument using aerogel sheets with dimensions of $125 \times 10 \times 10 \mathrm{~mm}^{3}$. CCT was performed using a Fire Testing Technology cone calorimeter on samples of $100 \times$ $100 \times 10 \mathrm{~mm}^{3}$ dimensions, according to ISO $5660-1$, with an external heat flux of $50 \mathrm{~kW} / \mathrm{m}^{2}$.

The flame-spraying experiment was conducted using a butane flame with a central flame temperature of $1300^{\circ} \mathrm{C}$. The flame was perpendicular to the surface of the aerogel samples, which were $40 \times 40 \times 6 \mathrm{~mm}^{3}$ in size. The distance between the flame tip and the sample was fixed at $60 \mathrm{~mm}$. The temperature on the backside of the aerogel was measured using an infrared thermometer at $1 \mathrm{~min}$ intervals. Triplicate measurements were conducted for each sample.

The mechanical performance of the composites was examined using Instron universal test machine UT4304 (SANS Instrument Co., Ltd., Shanghai, China) at a crosshead speed of $20 \mathrm{~mm} / \mathrm{min}$. The sample size was $150 \times 10 \times 4 \mathrm{~mm}$

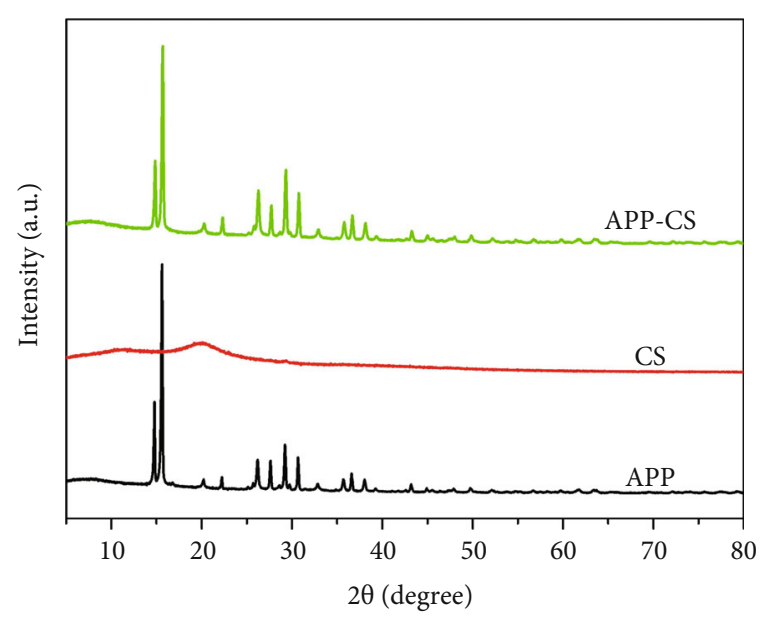

FIGURE 4: XRD patterns of APP, CS, and APP-CS.

for the tensile test. Compression strength was conducted using an electronic universal testing machine (CMT4104, SANS Co., Ltd., China), fitted with a $10 \mathrm{kN}$ load cell, at a crosshead of $20 \mathrm{~mm} / \mathrm{min}$. The dimension of all samples is about $20 \mathrm{~mm}$ in diameter and height.

Rheological properties were characterized by using an Anton Paar Physica MCR 301 rotational rheometer equipped with a CTD 450 convection oven (Graz, Austria). The dynamic frequency scanning tests were performed in the range of $0.01-100 \mathrm{rad} \mathrm{s}^{-1}$ at $110^{\circ} \mathrm{C}$. 


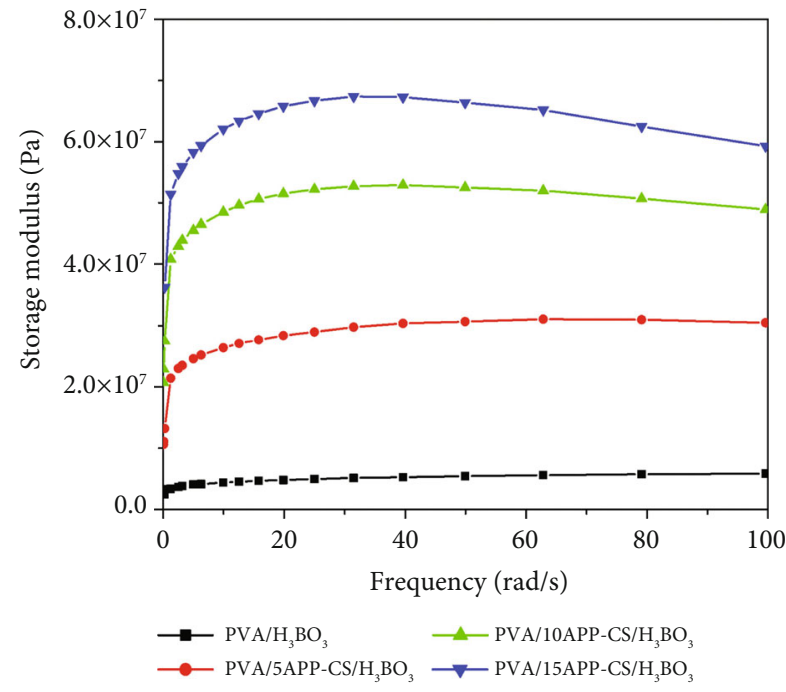

(a)

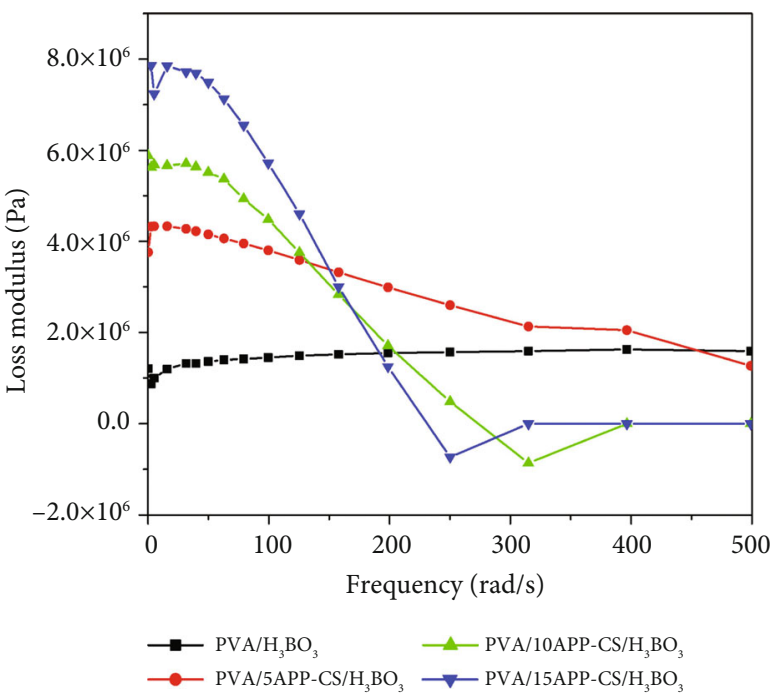

(b)

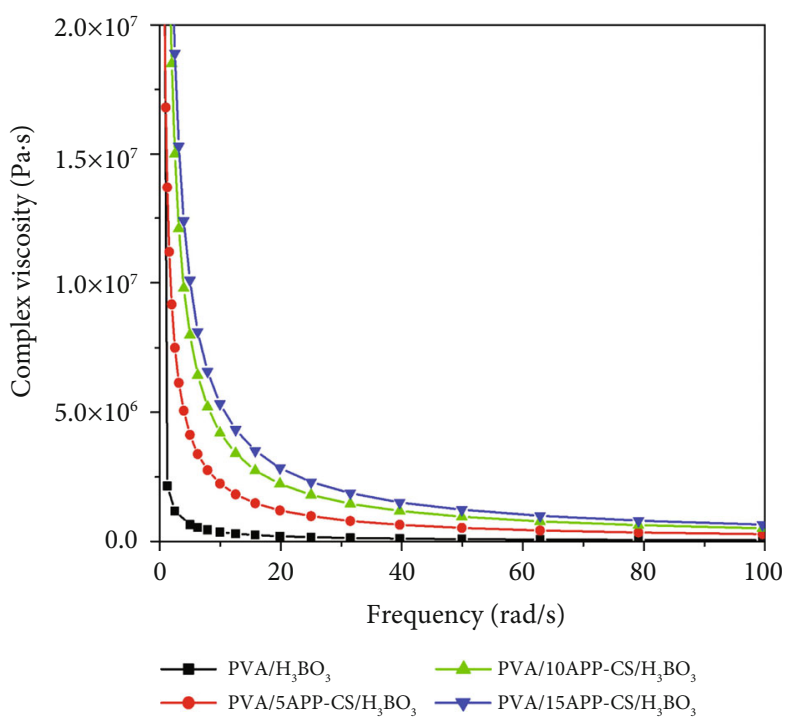

(c)

FIGURE 5: Dependence of (a) $G^{\prime}$, (b) $G^{\prime \prime}$, and (c) $\eta^{*}$ on frequency for the PVA composite aerogels.

\section{Results and Discussion}

3.1. Characterization of the APP-CS Composite. FTIR spectroscopy was used to obtain direct evidence of chemical reactions between APP and CS (Figure 2). The characteristic absorption bands of APP at 3400-3000, 1430, 1242, 1072, 1016 , and $877 \mathrm{~cm}^{-1}$ are ascribed to $-\mathrm{NH}_{4}{ }^{+},-\mathrm{NH}_{4}{ }^{+}, \mathrm{P}=\mathrm{O}$, $\mathrm{PO}$ (symmetric stretching), $\mathrm{PO}_{2}$, and $\mathrm{POP} / \mathrm{PO}$ (asymmetric stretching), respectively [12]. The characteristic absorption bands observed at 3500-3300, 1620, 1430, 1378, 1160, 1079, and $1032 \mathrm{~cm}^{-1}$ for $\mathrm{CS}$ are ascribed to $-\mathrm{OH}$ and $-\mathrm{NH}_{2}$, $\mathrm{C}=\mathrm{O}, \mathrm{O}-\mathrm{H},(\mathrm{CN}$, amide), (CO, bridge oxygen), (COC component), and (COC component), respectively [13-15]. The FTIR spectrum of APP-CS showed no apparent differences as compared with that of APP. This indicates that either no new derivatives were formed by the reaction of APP and CS or the APP peaks were of high intensity and overlapped with the CS peaks. APP and CS carry negative and positives charges, respectively, and form a polyelectrolyte complex through hydrogen bonding and ionic interaction (Figure 3).

Further, the absence of chemical reactions between APP and CS was also confirmed by XRD (Figure 4). The XRD pattern of CS, which is semicrystalline in nature, yields typical broad diffraction peaks at $\sim 10^{\circ}$ and $20^{\circ}$ [16]. APP, which is crystalline, yields sharp characteristic peaks at $14.6^{\circ}, 15.5^{\circ}$, $20.2^{\circ}, 26^{\circ}, 27.5^{\circ}, 29.1^{\circ}, 30.5^{\circ}, 35.6^{\circ}, 36.5^{\circ}, 37.9^{\circ}$, and $43.2^{\circ}$ [17-19]. No obvious differences could be identified between the XRD patterns of APP and APP-CS.

3.2. Rheological Properties of PVA Composite Hydrogels. The composite of PVA/ $\mathrm{H}_{3} \mathrm{BO}_{3}$ and APP-CS formed a doublenetwork hydrogel system. To study the bonding in the PVA composite hydrogels, their rheological properties were evaluated (Figure 5). In the frequency range of $0-100 \mathrm{rad} / \mathrm{s}$, the 


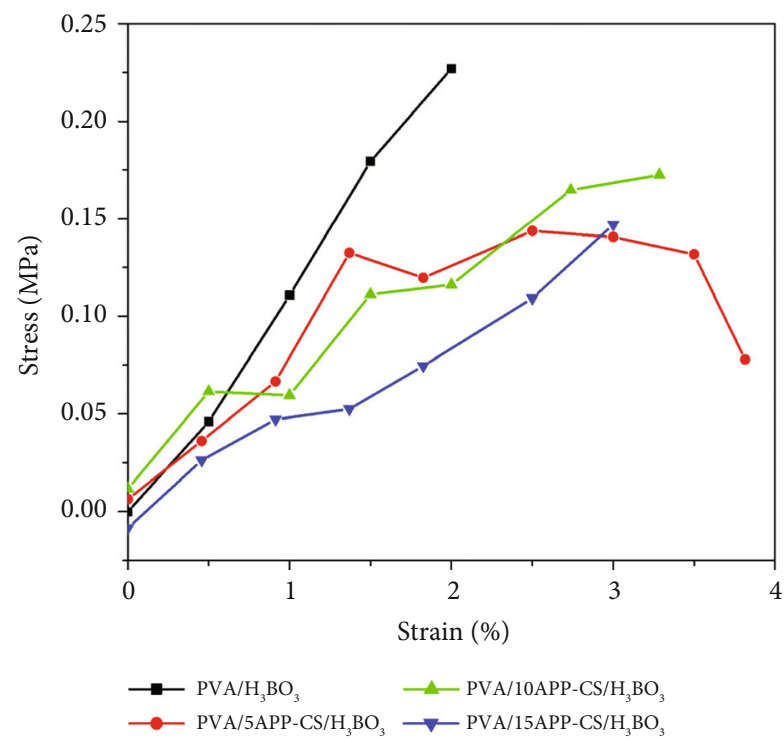

(a)

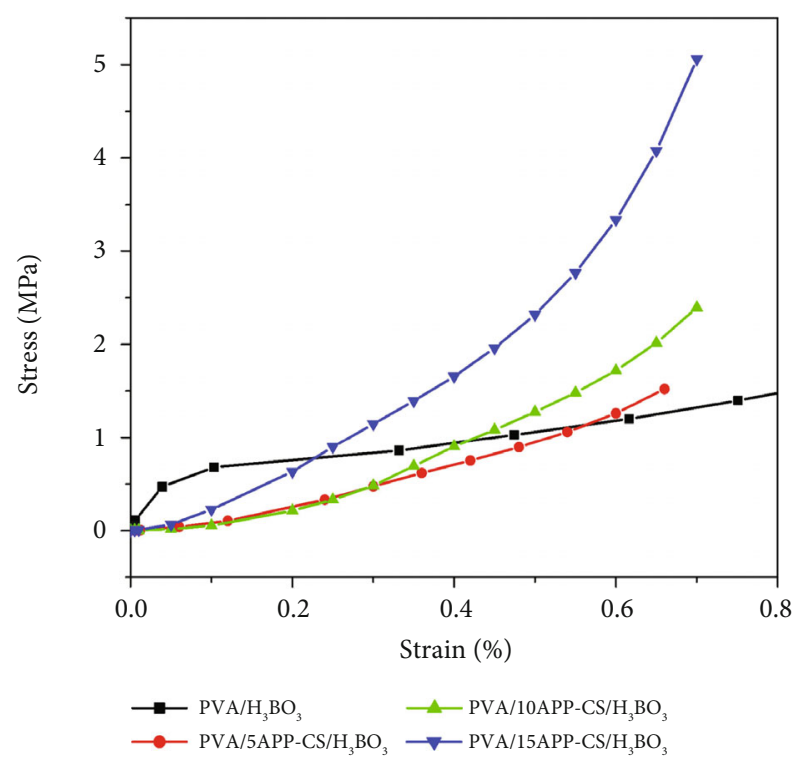

(b)

FIGURE 6: (a) Stress-strain and (b) compressive stress-strain curves of the PVA composite aerogels.

storage modulus $\left(G^{\prime}\right)$ was greater than the loss modulus $\left(G^{\prime \prime}\right)$, and the PVA composite hydrogels behaved like an elastic gel. The $G^{\prime}$ values increased with increasing APP-CS content in the hydrogel. This suggests that with higher APP-CS content, APP and CS exhibit stronger interactions to form a polyelectrolyte through ionic interaction, which results in a higher storage modulus $\left(G^{\prime}\right)$.

All samples exhibit a decrease in viscosity $\left(\eta^{*}\right)$ with the increasing shear rate and finally approached zero at $100 \mathrm{rad} / \mathrm{s}$ (Figure 5(c)). That is, the PVA-based hydrogel changed from a gel state to a quasi-liquid state. This indicates that the crosslinking bonds between PVA and $\mathrm{H}_{3} \mathrm{BO}_{3}$, as well as the ionic interactions between APP and CS, were likely destroyed with the increasing shear rate.

3.3. Mechanical Properties. The stress-strain curves of the hydrogels are displayed in Figure 6(a). The strain at break of the hydrogels increased with the APP-CS content; however, the tensile strength decreased (Figure 7). This is because APP-CS acted as a filler in the PVA-based aerogel. That is, as the APP-CS content increased, the crosslinking density decreased, resulting in an increased strain at break and compromised tensile strength. However, the tensile strength did not significantly vary between the samples.

Figure 6(b) clearly demonstrates that the APP-CS content has a negligible effect on the compressive stress-strain curves of the hydrogel samples, indicating that the overall mechanical properties of the PVA composite aerogels did not change with the addition of APP-CS. In addition, the peak stress value increased with increasing APP-CS content.

3.4. Basic Features of the PVA Composite Aerogels. The density, thermal conductivity, and porosity of the aerogels containing APP-CS are listed in Table 1. The SEM image (Figure 8) shows that the aerogel without APP-CS had a few pores, and it easily collapsed because it was not sup-

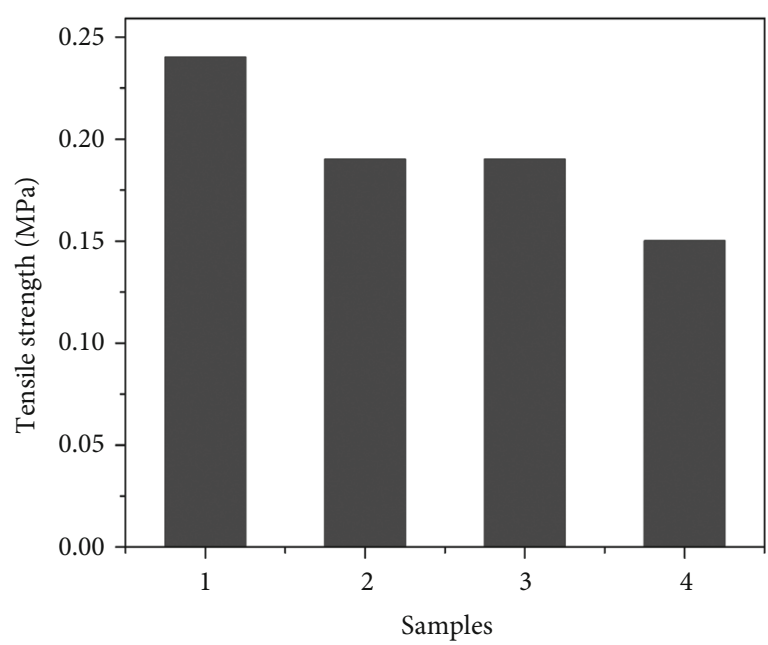

FIgURe 7: Tensile strengths of the PVA composite hydrogels with different APP-CS contents.

ported by APP and CS. In contrast, the aerogels with APPCS had a porous microstructure. However, the porosity of the aerogels with higher APP-CS content (10 g and $15 \mathrm{~g}$ ) decreased owing to the barrier effect created by APP-CS, which increases the thermal conductivity and density of the samples.

3.5. Thermal Stability of the PVA Composite Aerogels. The effect of APP-CS on the thermal stability of the PVA-based aerogels was determined by TGA of the PVA composite aerogels with different amounts of APP-CS. Figure 9 shows the respective TG and DTG curves, and the corresponding data are listed in Table 2. $T_{5 \%}$ is defined as the initial decomposition temperature. The $T_{5 \%}$ of the PVA composite aerogels with APP-CS is higher than that of the PVA aerogel 
TABle 1: Density, thermal conductivity, and porosity of the PVA composite aerogels.

\begin{tabular}{lcccc}
\hline Sample ID & Composites & Density $\left(\mathrm{g} / \mathrm{cm}^{3}\right)$ & Thermal conductivity $(\mathrm{W} / \mathrm{mK})$ & Porosity $(\%)$ \\
\hline 1 & $\mathrm{PVA} / \mathrm{H}_{3} \mathrm{BO}_{3}$ & $0.635 \pm 0.002$ & $0.1223 \pm 0.0003$ & 73.2 \\
2 & $\mathrm{PVA} / 5 \mathrm{APP}-\mathrm{CS} / \mathrm{H}_{3} \mathrm{BO}_{3}$ & $0.482 \pm 0.001$ & $0.0910 \pm 0.0003$ & 87.1 \\
3 & $\mathrm{PVA} / 10 \mathrm{APP}-\mathrm{CS} / \mathrm{H}_{3} \mathrm{BO}_{3}$ & $0.644 \pm 0.002$ & $0.1239 \pm 0.0003$ & 83.0 \\
4 & $\mathrm{PVA} / 15 \mathrm{APP}-\mathrm{CS} / \mathrm{H}_{3} \mathrm{BO}_{3}$ & $0.763 \pm 0.002$ & $0.1279 \pm 0.0003$ & 78.3 \\
\hline
\end{tabular}

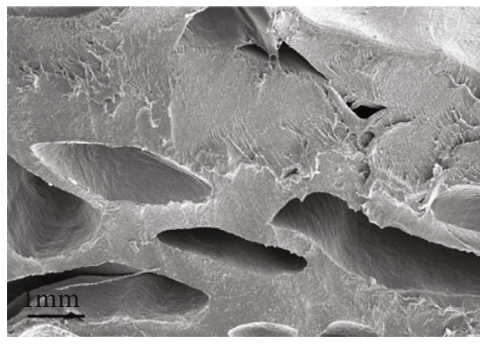

(a)

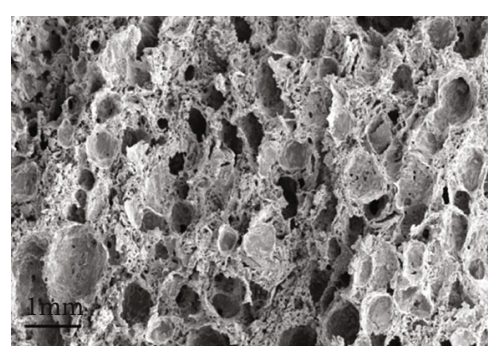

(c)

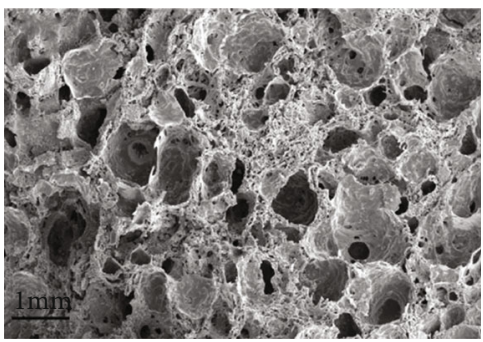

(b)

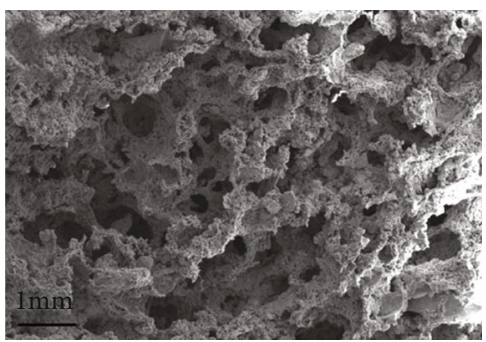

(d)

FIGURE 8: SEM images of the PVA composite aerogels: (a) $\mathrm{PVA} / \mathrm{H}_{3} \mathrm{BO}_{3}$, (b) $\mathrm{PVA} / 5 \mathrm{APP}-\mathrm{CS} / \mathrm{H}_{3} \mathrm{BO}_{3}$, (c) $\mathrm{PVA} / 10 \mathrm{APP}-\mathrm{CS} / \mathrm{H}_{3} \mathrm{BO} \mathrm{O}_{3}$, and (d) $\mathrm{PVA} / 15 \mathrm{APP}-\mathrm{CS} / \mathrm{H}_{3} \mathrm{BO}_{3}$.

without APP-CS (Table 2), indicating that APP-CS improved the thermal stability of the composites. The weight loss observed below $100^{\circ} \mathrm{C}$ is attributed to the removal of water from the aerogel, which contains a large amount of water. The highest weight loss at $200-500^{\circ} \mathrm{C}$ is attributed to the decomposition of the PVA backbone [20]. Further, the decomposition peak at $280-370^{\circ} \mathrm{C}$ is attributed to the degradation of APP-CS into polyphosphoric acid, which catalyzes the dehydration reaction between the -OH group of APP and the $-\mathrm{NH}_{2}$ group of CS. This causes an increase in the char residue of the PVA composite aerogels at $700^{\circ} \mathrm{C}$ as compared to that of the $\mathrm{PVA} / \mathrm{H}_{3} \mathrm{BO}_{3}$ without APP-CS (residual char content: $10.3 \%)$.

In particular, the aerogel containing $15 \mathrm{~g}$ APP-CS (APP : $\mathrm{CS}=3: 1$ mass ratio) generated $47.5 \%$ of residual char. This implies that CS in combination with APP has an excellent char-forming capacity and may significantly improve the flame retardancy of the PVA-based aerogels $[21,22]$. The intumescent char layer provides a strong protective barrier (condensed-phase flame retardancy), which prevents the contact of oxygen with the substrate and the subsequent heat transfer, thereby preventing further burning of the substrate [23-25].

3.6. Combustion Behaviors of the PVA Composite Aerogels. The UL-94 vertical burning test has been widely used to eval- uate the flame retardancy of materials [26-28]. The results obtained for the PVA composite aerogels are listed in Table 3. When APP-CS were added to $\mathrm{PVA} / \mathrm{H}_{3} \mathrm{BO}_{3}$, the UL-94 rating increased from $\mathrm{NR}$ to $\mathrm{V}-0$ and the dripping phenomenon was improved. The synergistic effect of APP and CS was clearly manifested, which is consistent with the TGA results.

CCT is a useful tool for evaluating flame-retardant materials and can be used to simulate real fire conditions [29-31]. The time to ignition (TTI), total heat release rate (THR), heat release rate (HRR), and carbon dioxide $\left(\mathrm{CO}_{2}\right)$ production are presented in Figure 10 and Table 4. A longer TTI implies that the material is difficult to burn and has better flame retardancy. The TTI of the PVA/ $\mathrm{H}_{3} \mathrm{BO}_{3}$ was only $66 \mathrm{~s}$, while that of the PVA composite aerogel increased with increasing APP-CS content. Thus, it indicates an improved flame retardancy in the latter.

The HRR curves of the aerogels are shown in Figure $10(\mathrm{a})$. The peak HRR (PHRR) of the $\mathrm{PVA} / \mathrm{H}_{3} \mathrm{BO}_{3}$ was $294.9 \mathrm{~kW} / \mathrm{m}^{2}$, while that of the PVA composite aerogels with $15 \mathrm{~g}$ APP-CS (APP : $\mathrm{CS}=3: 1$ mass ratio) was decreased to $68.1 \mathrm{~kW} / \mathrm{m}^{2}$ (Table 4). Furthermore, the THR curves presented in Figure 10(b) show considerable differences, while those of the PVA composite aerogels with APP-CS were decreased to $17.5 \mathrm{MJ} / \mathrm{m}^{2}$. This indicates that the PVA composite aerogel with APP-CS reduced the THR 


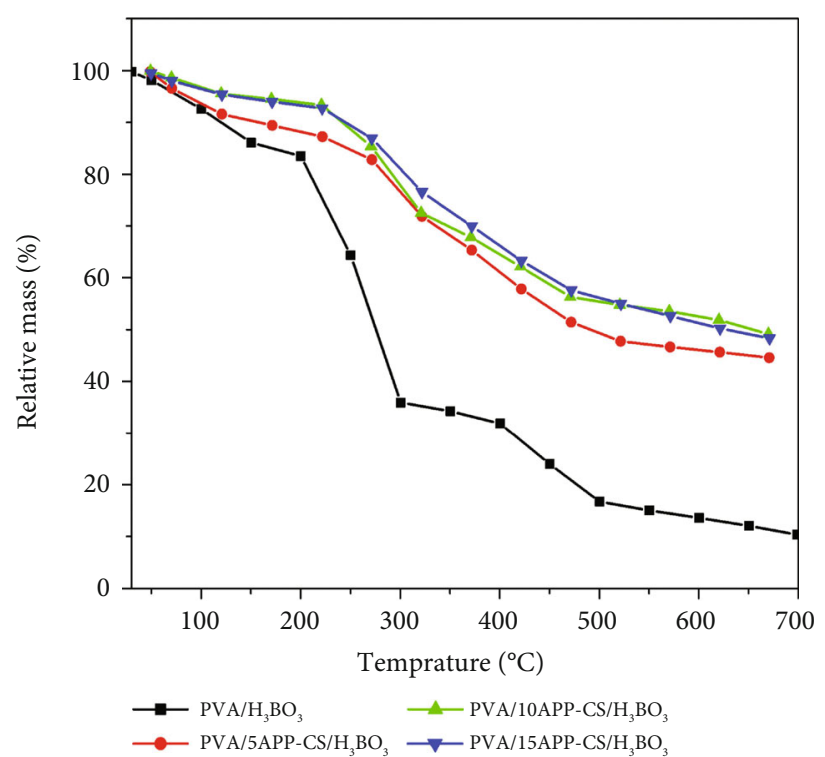

(a)

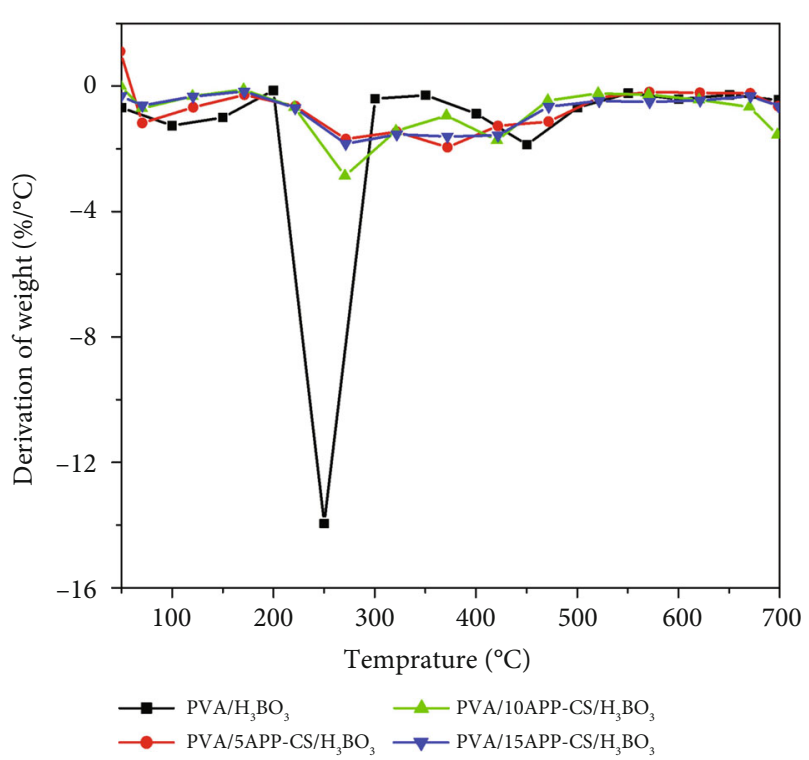

(b)

FIGURE 9: (a) TGA weight loss and (b) the corresponding DTG curves of the PVA composite aerogels.

TABLE 2: TGA data of the flame-retardant composites obtained in $\mathrm{N}_{2}$.

\begin{tabular}{lccccc}
\hline Sample ID & Composites & $T_{5 \%}\left({ }^{\circ} \mathrm{C}\right)$ & $R_{\max }\left(\% \cdot \min ^{-1}\right)$ & $T_{\max }\left({ }^{\circ} \mathrm{C}\right)$ & Residue at $700^{\circ} \mathrm{C}(\%)$ \\
\hline 1 & PVA $/ \mathrm{H}_{3} \mathrm{BO}_{3}$ & 81.5 & 14.0 & 250.4 & 10.3 \\
2 & $\mathrm{PVA} / 5 \mathrm{APP}-\mathrm{CS} / \mathrm{H}_{3} \mathrm{BO}_{3}$ & 83.1 & 2.9 & 290.1 & 46.1 \\
3 & $\mathrm{PVA} / 10 \mathrm{APP}-\mathrm{CS} / \mathrm{H}_{3} \mathrm{BO}_{3}$ & 138.8 & 3.3 & 284.3 & 47.3 \\
4 & $\mathrm{PVA} / 15 \mathrm{APP}-\mathrm{CS} / \mathrm{H}_{3} \mathrm{BO}_{3}$ & 132.8 & 2.4 & 294.6 & 47.5 \\
\hline
\end{tabular}

TABle 3: UL-94 test results of the PVA composite aerogels.

\begin{tabular}{|c|c|c|c|c|c|c|}
\hline \multirow{2}{*}{ Sample ID } & \multirow{2}{*}{ Composites } & \multicolumn{5}{|c|}{ UL-94 test $(3.2 \mathrm{~mm})$} \\
\hline & & $t_{1}(\mathrm{~s})$ & $t_{2}(\mathrm{~s})$ & Dripping & Ignite cotton & Rating \\
\hline 1 & $\mathrm{PVA} / \mathrm{H}_{3} \mathrm{BO}_{3}$ & 35 & 4 & Yes & Yes & NR \\
\hline 2 & $\mathrm{PVA} / 5 \mathrm{APP}-\mathrm{CS} / \mathrm{H}_{3} \mathrm{BO}_{3}$ & 5 & 17 & No & Yes & $\mathrm{V}-1$ \\
\hline 3 & PVA/10APP-CS/ $\mathrm{H}_{3} \mathrm{BO}_{3}$ & 3 & 1 & No & No & $\mathrm{V}-0$ \\
\hline 4 & PVA/15APP-CS/ $\mathrm{H}_{3} \mathrm{BO}_{3}$ & 2 & 1 & No & No & $\mathrm{V}-0$ \\
\hline
\end{tabular}

of the fuel available for combustion. Similarly, the $\mathrm{CO}_{2}$ output decreased with increasing APP-CS content (Figure 10(c)). The fire growth rate (FGR) (Table 4) reveals that the $\mathrm{PVA} / \mathrm{H}_{3} \mathrm{BO}_{3}$ was easy to flash, implying a higher fire risk. However, when APP-CS were added, the FGR decreased considerably to $0.28 \mathrm{~kW} / \mathrm{m}^{2} \mathrm{~s}$, indicating that this aerogel can significantly increase the chance of withstanding an indoor fire.

To further study the flame-retardant mechanism, the morphology of the char layer of the aerogels was characterized by SEM (Figure 11), which shows increased residual char after combustion and a significant improvement in the integrity of the char layer. A dense and integrated char layer formed on the surface of the composite material can act as a physical barrier to decrease heat and mass transfer, thereby reducing the flammability of the composite. During combus- tion, $\mathrm{PVA} / \mathrm{H}_{3} \mathrm{BO}_{3}$ decomposes into carbon [32]. Moreover, APP-CS also decomposes into carbon because APP decomposes into polyphosphoric acid, which catalyzes the dehydration reaction between the -OH groups of APP and -the $\mathrm{NH}_{2}$ groups of CS. The expanded char layer formed by the degradation of $\mathrm{PVA} / \mathrm{H}_{3} \mathrm{BO}_{3}$ and APP-CS synergistically inhibits the heat and mass transfer to the underlying material, thereby preventing further flaming of the substrate.

To study the fire resistance of the aerogels, a flamespraying experiment was conducted out using a butane flame, as depicted in Figure 12(a). The temperature-time curve is shown in Figure 12(b). For all the aerogels, the temperature measured on the backside of the aerogels increased with time. The maximum temperature of the $\mathrm{PVA} / \mathrm{H}_{3} \mathrm{BO}_{3}$ was $256.4^{\circ} \mathrm{C}$, while the maximum temperature of the 


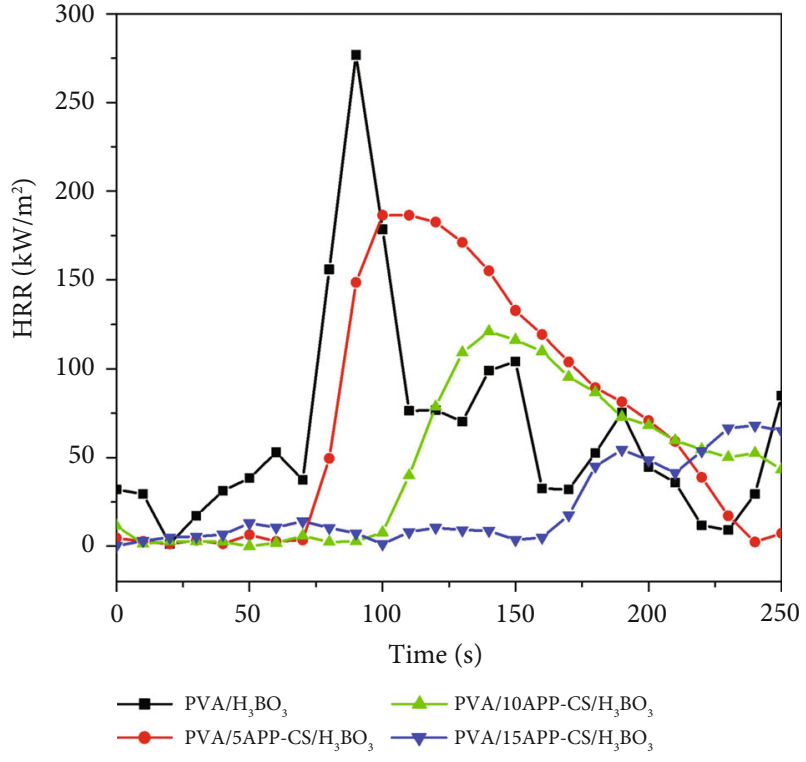

(a)

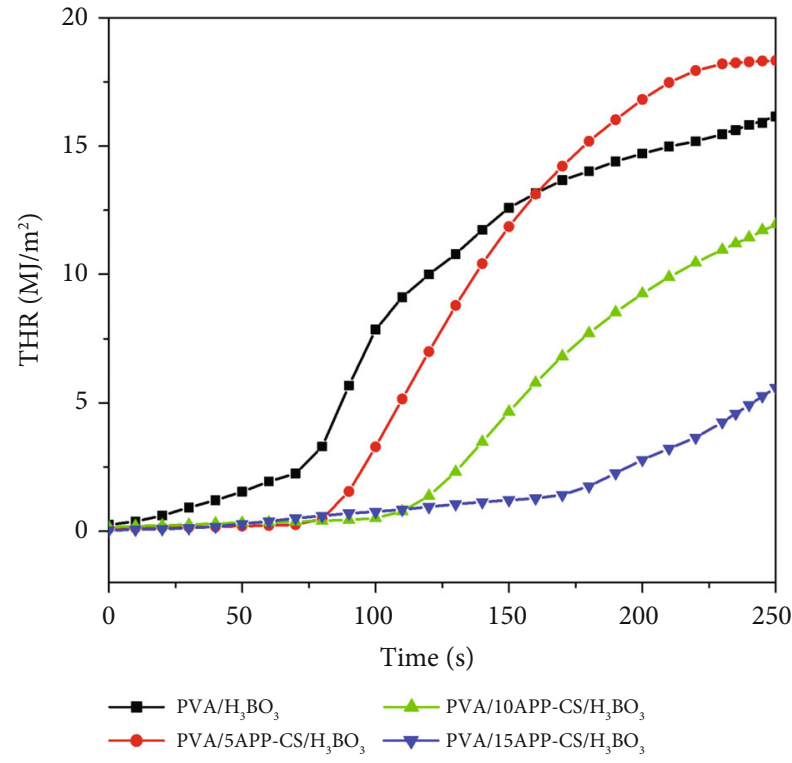

(b)

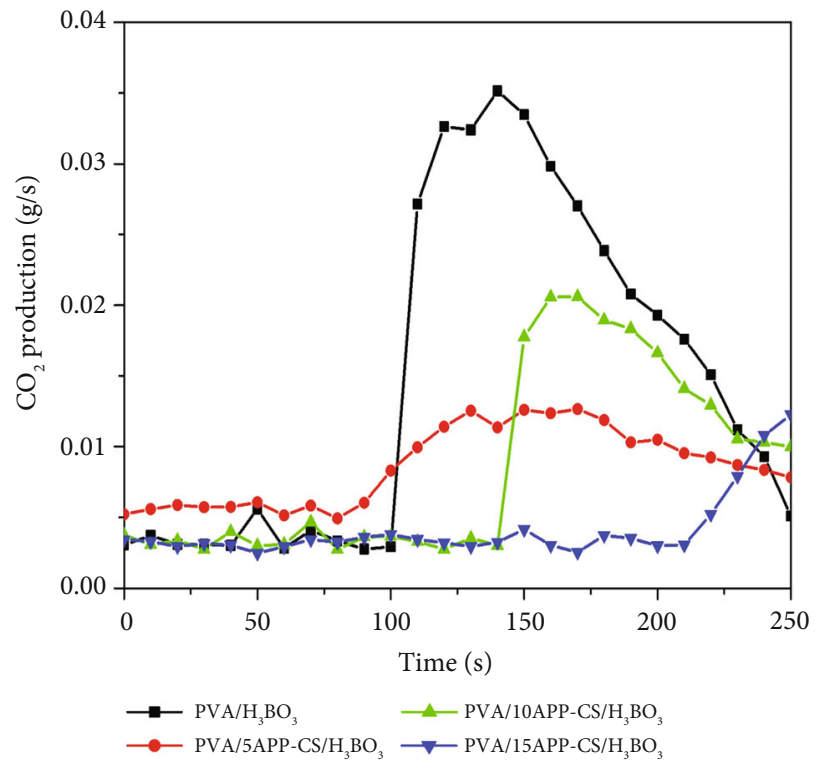

(c)

FIGURE 10: (a) Heat release rate (HRR), (b) total heat release rate (THR), and (c) $\mathrm{CO}_{2}$ production curves of the PVA composite aerogels.

TABLE 4: Combustion parameters obtained from cone calorimeter tests.

\begin{tabular}{|c|c|c|c|c|c|c|c|}
\hline Sample ID & Composites & TTI (s) & $\operatorname{PHRR}\left(\mathrm{kW} / \mathrm{m}^{2}\right)$ & $\operatorname{THR}\left(\mathrm{MJ} / \mathrm{m}^{2}\right)$ & $\mathrm{TTPHRR}^{\mathrm{a}}(\mathrm{s})$ & $\operatorname{TSR}^{\mathrm{b}}\left(\mathrm{m}^{2} / \mathrm{m}^{2}\right)$ & $\mathrm{FGR}^{\mathrm{c}}\left(\mathrm{kW} / \mathrm{m}^{2} \mathrm{~s}\right)$ \\
\hline 1 & $\mathrm{PVA} / \mathrm{H}_{3} \mathrm{BO}_{3}$ & 66 & 294.9 & 21.5 & 88 & 273.0 & 3.35 \\
\hline 2 & $\mathrm{PVA} / 5 \mathrm{APP}-\mathrm{CS} / \mathrm{H}_{3} \mathrm{BO}_{3}$ & 67 & 189.6 & 19.3 & 107 & 641.2 & 1.69 \\
\hline 3 & $\mathrm{PVA} / 10 \mathrm{APP}-\mathrm{CS} / \mathrm{H}_{3} \mathrm{BO}_{3}$ & 76 & 121.1 & 17.8 & 140 & 480.9 & 0.86 \\
\hline 4 & PVA/15APP-CS $/ \mathrm{H}_{3} \mathrm{BO}_{3}$ & 156 & 68.1 & 17.5 & 240 & 716.6 & 0.28 \\
\hline
\end{tabular}

${ }^{a}$ TTPHRR $=$ time to PHRR. ${ }^{b}$ TSR $=$ total smoke release. ${ }^{c} \mathrm{FGR}=\mathrm{PHRR} / \mathrm{T}_{\mathrm{PHRR}}$.

composite aerogels with $15 \mathrm{~g}$ APP-CS (APP : CS $=3: 1$ mass ratio) was $219.6^{\circ} \mathrm{C}$. The higher the APP-CS content, the lower the temperature, indicating that the aerogels were thermally insulating to a certain degree.
Figure 12(c) shows the aerogels after burning for $10 \mathrm{~min}$. It is apparent that the PVA/ $\mathrm{H}_{3} \mathrm{BO}_{3}$ was quickly ignited, was easily deformed, and had a smaller carbon area. However, the composite aerogels showed better structural integrity 


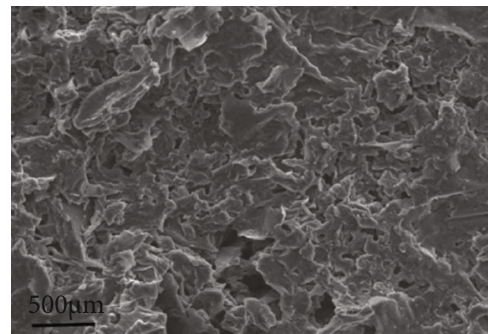

(a)

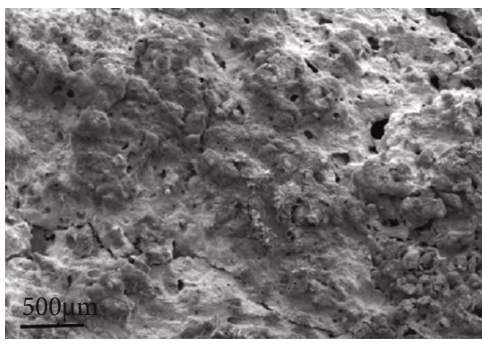

(c)

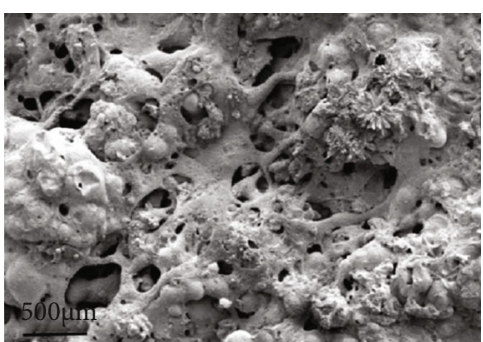

(b)

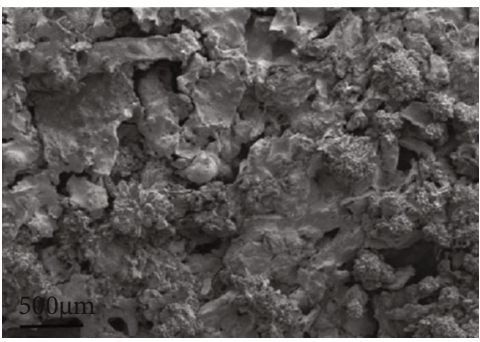

(d)

FIgURE 11: SEM images of the char residues of the PVA composite aerogels: (a) $\mathrm{PVA} / \mathrm{H}_{3} \mathrm{BO}_{3}$, (b) $\mathrm{PVA} / 5 \mathrm{APP}-\mathrm{CS} / \mathrm{H}_{3} \mathrm{BO}$, (c) PVA/ $10 \mathrm{APP}-\mathrm{CS} / \mathrm{H}_{3} \mathrm{BO}_{3}$, and (d) PVA/15APP-CS/ $\mathrm{H}_{3} \mathrm{BO}_{3}$.
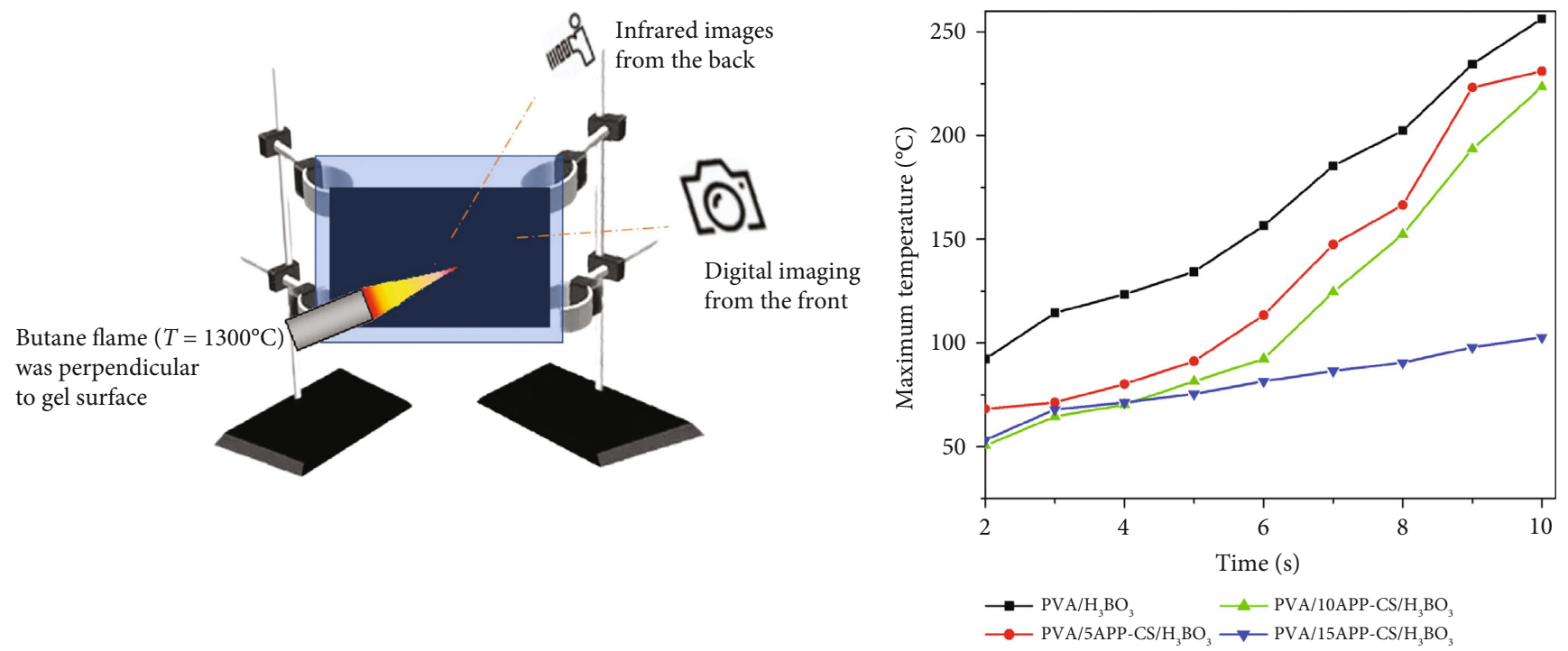

(a)

(b)

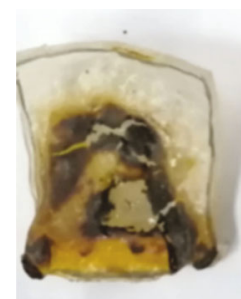

1

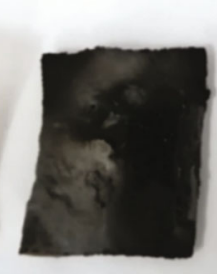

2

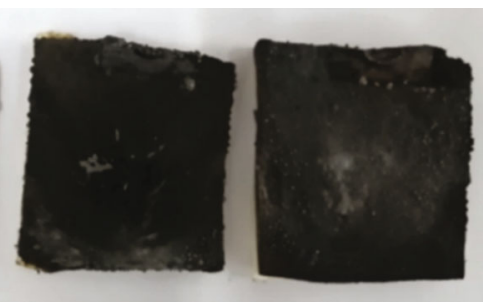

4

(c)

FIGURE 12: Fire resistance of the PVA-based aerogels. (a) Schematic of the fire resistance test. (b) Maximum temperature at the back of the aerogels versus time. (c) Photographs of the samples after burning for $10 \mathrm{~min}$. 
(i.e., the shape was retained) with increasing APP-CS content. After burning for $10 \mathrm{~min}$, the PVA composite aerogel substrates with APP-CS remained impervious to the flames, indicating that APP-CS improved the thermal insulation and flame retardancy of the PVA-based aerogel.

\section{Conclusion}

In this study, two flame-retardant materials, ammonium polyphosphate and chitosan, were added to $\mathrm{PVA} / \mathrm{H}_{3} \mathrm{BO}_{3}$ to prepare aerogels by a freeze-drying method. The anionic APP and cationic CS formed a polyelectrolyte complex by ionic interaction. It was observed that the APP-CS composite decreased the PHRR and THR values and $\mathrm{CO}_{2}$ emission of the PVA-based aerogels owing to the formation of a char layer by the decomposition of $\mathrm{PVA} / \mathrm{H}_{3} \mathrm{BO}_{3}$ and APP-CS during combustion. The expanded char layer exerts a flame-retardant effect on the PVA-based aerogel. In addition, the PVA composite aerogels with a porous structure have an excellent thermal insulation property and low thermal conductivity (as low as $0.0879 \mathrm{~W} \mathrm{~m}^{-1} \mathrm{~K}^{-1}$ ). Hence, the PVA composite aerogels with good flame-retardant and thermal insulation properties can be potentially applied to building materials.

\section{Data Availability}

The data used to support the findings of this study are included within the supplementary information files.

\section{Conflicts of Interest}

The authors declare that there is no conflict of interest regarding the publication of this paper.

\section{Acknowledgments}

We would like to thank Editage (http://www.editage.com/) for English language editing.

\section{Supplementary Materials}

Supplementary Materials contains the data files which are used in this study. (Supplementary Materials)

\section{References}

[1] W. Liang, R. Wang, C. Wang et al., "Facile preparation of attapulgite-based aerogels with excellent flame retardancy and better thermal insulation properties," Journal of Applied Polymer Science, vol. 136, no. 32, article 47849, 2019.

[2] W. Yang, N.-N. Wang, P. Ping et al., "Novel 3D network architectured hybrid aerogel comprising epoxy, graphene, and hydroxylated boron nitride nanosheets," ACS Applied Materials \& Interfaces, vol. 10, no. 46, pp. 40032-40043, 2018.

[3] L. Zuo, Y. Zhang, L. Zhang, Y. E. Miao, W. Fan, and T. Liu, "Polymer/carbon-based hybrid aerogels: preparation, properties and applications," Materials, vol. 8, no. 10, pp. 68066848, 2015.

[4] Y. Zhang, W. Fan, H. Lu, and T. Liu, "Highly porous polyimidederived carbon aerogel as advanced three-dimensional frame- work of electrode materials for high-performance supercapacitors," Electrochimica Acta, vol. 283, pp. 1763-1772, 2018.

[5] M. Farooq, M. H. Sipponen, A. Seppala, A. Seppälä, and M. Österberg, "Eco-friendly flame-retardant cellulose nanofibril aerogels by incorporating sodium bicarbonate," ACS Applied Materials \& Interfaces, vol. 10, no. 32, pp. 2740727415, 2018.

[6] E. Chiellini, A. Corti, P. Cinelli, and S. D'Antone, "Biodegradation of poly (vinyl alcohol) based materials," Progress in Polymer Science, vol. 28, no. 6, pp. 963-1014, 2003.

[7] D. J. Irvine, J. A. McCluskey, and I. M. Robinson, "Fire hazards and some common polymers," Polymer Degradation and Stability, vol. 67, no. 3, pp. 383-396, 2000.

[8] G. E. Zaikov and S. M. Lomakin, "Ecological issue of polymer flame retardancy," Journal of Applied Polymer Science, vol. 86, no. 10, pp. 2449-2462, 2002.

[9] M.-J. Chen, X. Wang, X.-L. Li et al., "The synergistic effect of cuprous oxide on an intumescent flame-retardant epoxy resin system," RSC Advances, vol. 7, no. 57, pp. 35619-35628, 2017.

[10] J. Chen, H. Xie, X. Lai, H. Li, J. Gao, and X. Zeng, “An ultrasensitive fire-warning chitosan/montmorillonite/carbon nanotube composite aerogel with high fire-resistance," Chemical Engineering Journal, vol. 399, article 125729, 2020.

[11] R. Chen, Z. Luo, X. Yu, H. Tang, Y. Zhou, and H. Zhou, “Synthesis of chitosan-based flame retardant and its fire resistance in epoxy resin," Carbohydrate Polymers, vol. 245, article 116530, 2020.

[12] D. Jiang, M. Pan, X. Cai, and Y. Zhao, "Flame retardancy of rice straw-polyethylene composites affected by_in situ_polymerization of ammonium polyphosphate/silica," Composites Part A-Applied Science and Manufacturing, vol. 109, pp. 1-9, 2018.

[13] J. Jagiello, J. Judek, M. Zdrojek, M. Aksienionek, and L. Lipinska, "Production of graphene composite by direct graphite exfoliation with chitosan," Materials Chemistry and Physics, vol. 148, no. 3, pp. 507-511, 2014.

[14] X. Xu, B. Bai, H. Wang, and Y. Suo, "Synthesis of human hair fiber-impregnated chitosan beads functionalized with citric acid for the adsorption of lysozyme," RSC Advances, vol. 7, no. 11, pp. 6636-6647, 2017.

[15] M. Fernandes Queiroz, K. R. Melo, D. A. Sabry, G. L. Sassaki, and H. A. Rocha, "Does the use of chitosan contribute to oxalate kidney stone formation?"” Marine Drugs, vol. 13, no. 1, pp. 141-158, 2015.

[16] T. Zhang, H. Yan, L. Shen et al., "Chitosan/phytic acid polyelectrolyte complex: a green and renewable intumescent flame retardant system for ethylene-vinyl acetate copolymer," Industrial \& Engineering Chemistry Research, vol. 53, no. 49, pp. 19199-19207, 2014.

[17] Z.-B. Shao, C. Deng, Y. Tan et al., “Ammonium polyphosphate chemically-modified with ethanolamine as an efficient intumescent flame retardant for polypropylene," Journal of Materials Chemistry A, vol. 2, no. 34, pp. 13955-13965, 2014.

[18] W. Chen, L. Wang, and G. Liu, "Synthesis of ammonium polyphosphate with crystalline form V (APP-V) from melamine polyphosphate (MPP)," Polymer Degradation and Stability, vol. 97, no. 12, pp. 2567-2570, 2012.

[19] S. Qiu, C. Ma, X. Wang et al., "Melamine-containing polyphosphazene wrapped ammonium polyphosphate: a novel multifunctional organic-inorganic hybrid flame retardant," Journal of Hazardous Materials, vol. 344, pp. 839-848, 2018. 
[20] K. Shang, W. Liao, and Y.-Z. Wang, "Thermally stable and flame-retardant poly(vinyl alcohol)/montmorillonite aerogel _via_ a facile heat treatment," Chinese Chemical Letters, vol. 29, no. 3, pp. 433-436, 2018.

[21] Y.-T. Wang, S.-F. Liao, K. Shang et al., "Efficient approach to improving the flame retardancy of poly(vinyl alcohol)/clay aerogels: incorporating piperazine-modified ammonium polyphosphate," ACS Applied Materials \& Interfaces, vol. 7, no. 3, pp. 1780-1786, 2015.

[22] W. Cai, N. Hong, X. Feng et al., "A facile strategy to simultaneously exfoliate and functionalize boron nitride nanosheets via Lewis acid-base interaction," Chemical Engineering Journal, vol. 330, pp. 309-321, 2017.

[23] K. M. Holder, M. E. Huff, M. N. Cosio, and J. C. Grunlan, "Intumescing multilayer thin film deposited on clay-based nanobrick wall to produce self-extinguishing flame retardant polyurethane," Journal of Materials Science, vol. 50, no. 6, pp. 2451-2458, 2015.

[24] H. Wei, Z. Zhu, H. Sun, P. Mu, W. Liang, and A. Li, "Graphene and poly (ionic liquid) modified polyurethane sponges with enhanced flame-retardant properties," Journal of Applied Polymer Science, vol. 134, no. 44, article 45477, 2018.

[25] Q. Zhang, X. Xu, D. Lin et al., "Hyperbolically patterned 3D graphene metamaterial with negative Poisson's ratio and superelasticity," Advanced Materials, vol. 28, no. 11, pp. 2229-2237, 2016.

[26] Y. Chen, J. Zhan, and P. Zhang, "Preparation of intumescent flame retardant poly(butylene succinate) using fumed silica as synergistic agent," Industrial and Engineering Chemistry Research, vol. 49, no. 17, pp. 8200-8208, 2010.

[27] P. Jamshidi, D. Ghanbari, and M. Salavati-Niasari, "Sonochemical synthesis of $\mathrm{La}(\mathrm{OH})_{3}$ nanoparticle and its influence on the flame retardancy of cellulose acetate nanocomposite," Journal of Industrial and Engineering Chemistry, vol. 20, no. 5, pp. 3507-3512, 2014.

[28] A. Subasinghe and D. Bhattacharyya, "Performance of different intumescent ammonium polyphosphate flame retardants in PP/kenaf fibre composites," Composites Part A: Applied Science and Manufacturing, vol. 65, pp. 91-99, 2014.

[29] X. Hu, Y. Li, and Y. Wang, "Synergistic effect of the charring agent on the thermal and flame retardant properties of polyethylene," Macromolecular Materials and Engineering, vol. 289, no. 2, pp. 208-212, 2004.

[30] Q. Ren, C. Wan, Y. Zhang, and J. Li, “An investigation into synergistic effects of rare earth oxides on intumescent flame retardancy of polypropylene/poly (octylene-co-ethylene) blends," Polymers for Advanced Technologies, vol. 22, no. 10, pp. 1414-1421, 2011.

[31] S. Nie, Y. Hu, L. Song, Q. He, D. Yang, and H. Chen, "Synergistic effect between a char forming agent (CFA) and microencapsulated ammonium polyphosphate on the thermal and flame retardant properties of polypropylene," Polymers for Advanced Technologies, vol. 19, no. 8, pp. 1077-1083, 2008.

[32] S.-T. Bee, K.-S. Lim, L. T. Sin, C. T. Ratnam, S. L. Bee, and A. R. Rahmat, "Interactive effect of ammonium polyphosphate and montmorillonite on enhancing flame retardancy of polycarbonate/acrylonitrile butadiene styrene composites," Iranian Polymer Journal, vol. 27, no. 11, pp. 899-911, 2018. 